\title{
Bile Acid Feeding Induces Cholangiocyte Proliferation and Secretion: Evidence for Bile Acid-Regulated Ductal Secretion
}

\author{
GIANFRANCO ALPINI,*,‡,§ SHANNON S. GLASER,* YOSHIYUKI UENO," REBECCA RODGERS,* \\ J O LYNNE PHINIZY,* HEATHER FRANCIS,* LEONARDO BAIOCCHI,* LEIGH A. HOLCOMB,,,$\|$ \\ ALESSANDRA CALIGIURI,* and GENE D. LESAGE* \\ Departments of * Internal Medicine, $¥$ Medical Physiology, and IPsychiatry and Behavioral Science, Scott \& White Hospital \\ and Texas A\&M University Health Science Center College of Medicine, and ${ }^{\S}$ Central Texas Veterans Health Care System, \\ Temple, Texas; and १Third Department of Internal Medicine, Tohoku University School of Medicine, Aobaku, Sendai, Japan
}

Background \& Aims: We have shown that taurocholate (TC) and taurolithocholate (TLC) interact in vitro with normal cholangiocytes, increasing DNA synthesis, secretin receptor (SR) gene expression, and adenosine $3^{\prime}, 5^{\prime}$-cyclic monophosphate (CAMP) synthesis. To further extend these in vitro studies, we tested the hypothesis that bile acids (BAs) directly stimulate cholangiocyte proliferation and secretion in vivo. Methods: After feeding with TC or TLC (1\% for $1-4$ weeks), we assessed the following in vivo: (1) ductal proliferation by both morphometry and immunohistochemistry for proliferating cell nuclear antigen (PCNA) and measurement of $\left[{ }^{3} \mathrm{H}\right]$ thymidine incorporation; and (2) the effect of secretin on bile secretion and bicarbonate secretion in vivo. Genetic expression of $\mathrm{H}_{3}$-histone and $\mathrm{SR}$ and intracellular CAMP levels were measured in isolated cholangiocytes. Results: After BA feeding, there was an increased number of PCNA-positive cholangiocytes and an increased number of ducts compared with control rats. $\left[{ }^{3} \mathrm{H}\right]$ Thymidine incorporation, absent in control cholangiocytes, was increased in cholangiocytes from BA-fed rats. In BA-fed rats, there was increased $S R$ gene expression (approximately 2.5-fold) and secretin-induced CAMP levels (approximately 3.0 -fold) in cholangiocytes, which was associated with de novo secretin-stimulated bile flow and bicarbonate secretion. Conclusions: These data indicate that elevated BA levels stimulate ductal secretion and cholangiocyte proliferation.

C holangiocytes that line the intrahepatic biliary tree secrete water and electrolytes in response to hormones. ${ }^{1-3}$ Secretin stimulates ductal bile secretion by interacting with secretin receptor (SR) present only on cholangiocytes, ${ }^{2}$ resulting in increases in intracellular adenosine 3', 5' -cyclic monophosphate (CAM P) synthesis ${ }^{3,4}$

Cholangiocytes are normally in a quiescent state., ${ }^{3,4}$ In experimental models of ductal hyperplasia, such as bile duct ligation (BDL) or $70 \%$ hepatectomy, cholangiocytes proliferate markedly, leading to enlargement of intrahe- patic ductal mass. ${ }^{1,3}$ Cholangiocyte proliferation is cl osely coupled with increased DN A synthesis, SR gene expression, secretin-induced CAMP synthesis, and secretinstimulated bicarbonate rich choleresis. ${ }^{1-3}$

Bile acids (BAs) interact with cholangiocytes and al ter cholangiocyte secretion and growth. ${ }^{4-8}$ To explain a bicarbonate-rich hypercholeresis after administration of certain BA, a "cholehepatic shunt pathway" has been proposed, suggesting that protonated BAs in the lumen of bile ducts are reabsorbed by cholangiocytes. ${ }^{7}$ Toxic hydrophobic BAs accumulate in both the blood circulation and liver in patients with chronic liver disease. Previous studies have shown toxicity of hydrophobic BAs to hepatocytes ${ }^{9,10}$ and bile ducts. ${ }^{11}$ W e have shown that, in vitro, both taurocholate (TC) and taurolithocholate (TLC) increase DN A synthesis, SR gene expression, and secretin-stimulated CAMP levels. ${ }^{4}$ Furthermore, we and others ${ }^{5,12}$ have shown functional and genetic expression of the sodium-dependent apical bileacid transporter (ABAT) in the cholangiocyte apical membranes. This $\mathrm{Na}^{+}$dependent ABAT probably plays an important rolein the $B A$ effects on cholangiocyte proliferation and secretion because BAs al ter cholangiocyte function in vitro only in the presence of sodium, and ABAT in cholangiocytes has a Michaelis constant $\left(K_{m}\right)$ for $T C$ similar to the BA concentration at which the maximum effects of $B A$ on cholangiocyte secretory and proliferative functions are observed in vitro. 4,12 Thus, we propose that uptake of BAs from bile by ABAT initiates signals that modulate cholangiocyte proliferation and secretion. ${ }^{4,12}$

In this study, we wanted to determine whether in-

Abbreviations used in this paper: $A B A T$, apical bile acid transporter; BA, bile acid; BDL, bile duct ligation; CK-19, cytokeratin 19; GAPDH, glyceraldehyde-3-phosphate dehydrogenase; GGT, $\boldsymbol{\gamma}$-glutamyl transferase; $\boldsymbol{\gamma}$-GT, $\boldsymbol{\gamma}$-glutamyltranspeptidase; KRH, KrebsHenseleit bicarbonate solution; SR, secretin receptor; TC, taurocholate; TLC, taurolithocholate.

(C) 1999 by the American Gastroenterological Association $0016-5085 / 99 / \$ 10.00$ 
creased biliary BA concentrations could directly stimulate in vivo cholangiocyte proliferation and ductal secretion in the absence of cholestasis or hepatic injury. We experimentally increased biliary BA concentration by feeding rats TC (a physiologically relevant BA) or TLC (which has been shown to induce ductal hyperplasia in rodents $^{8}$ ) for 1-4 weeks. There is enrichment ${ }^{13}$ and a 2-3-fold increase in the $B A$ pool ${ }^{14}$ with the administrated BA in BA-fed rats. In rats fed TC or TLC, we found that $B A$ concentrations were increased in bile but not in serum and that there was no biochemical or histological evidence of hepatic damage or cholestasis, yet there was cholangiocyte prol iferation and increased ductal secretion.

\section{Materials and Methods}

\section{Animal Model and Materials}

M ale Fischer 344 rats (125-150 g) from Charles River (Wilmington, MA) were used in the present studies. The animals were kept in a temperature-controlled environment $\left(20-22^{\circ} \mathrm{C}\right)$ with alternating 12 -hour light-dark cycles. The studies were conducted in rats fed $1 \%$ TC or $1 \%$ TLC, representing approximate doses of 275 and $260 \mu \mathrm{mol} /$ day, respectively, for $1-4$ weeks. Rat chow containing $1 \%$ TC, $1 \%$ TLC, or AIN 76 (control diet) was prepared by Dyets Inc. (Bethlehem, PA). Rats were fasted overnight before experiments. Before each protocol, rats were anesthetized with sodium pentobarbital (50 mg/kg intraperitoneally). Reagents were purchased from Sigma Chemical Co. (St. Louis, M O) unless otherwise indicated. N ( $\gamma$-L-glutamyl)-4-methoxy-2-naphthylamide, the substrate for $\gamma$-glutamyltranspeptidase $(\gamma-\mathrm{GT})$, was purchased from Polysciences (Warrington, PA). Both TC and TLC were purchased from Cal biochem-N ovabiochem Corp. (Lal olla, CA).

\section{Determination of Liver Inflammation and Hepatic Damage}

After TC or TLC feeding, the degree of liver inflammation was assessed by the grade system described by $D$ avis and $\mathrm{M}$ adri. ${ }^{15} \mathrm{H} \& \mathrm{E}$-stained liver sections were graded for the degree of inflammation in a coded fashion as follows: 0 , normal; +1 , triad-based; +2 , triad-based with focal parenchymal inflammation without necrosis; +4 , triad-based with lobular inflammation with unicellular necrosis; and +5 , confluent necrosis. To determine whether BA feeding induces liver damage, the serum levels of selected enzymes associated with hepatic damage (serum glutamic pyruvic transaminase [SG PT] , serum glutamic oxal acetic transaminase [SG OT], $\gamma$-glutamyl transferase (GGT), alkaline phosphatase, and both total and direct bilirubin) were measured by use of commercially available kits (Sigma).

\section{Purification of Cholangiocytes From Normal and BA-Fed Rats}

Pure (by $\gamma$-GT histochemistry; results not shown) preparations of cholangiocytes from control and BA-fed rats were obtained as previously described. 2,3,16,17 Briefly, after standard coll agenase perfusion, ${ }^{17}$ a cholangi ocyte-enriched fraction $(40 \%-55 \%$ pure by $\gamma-\mathrm{GT})$ was obtained from intact portal tracts, as described by Ishii et al.,17 and subsequently purified by immunoaffinity separation. 3,17

\section{Assessment of Intrahepatic Ductal Mass in Normal and BA-Fed Rats}

Intrahepatic duct mass was calculated by point count analysis $5^{3,18}$ by determination of the fraction of total matrix of points overlapping bile ducts, stained for $\gamma-\mathrm{GT},{ }^{19}$ in coded frozen liver sections $(6 \mu \mathrm{m})$ from normal and $B A$-fed rats $(n=$ 12). In each liver section, the entire area was examined by multiple photographs taken in a mosaic fashion. From the total number of points over hepatic tissue and the number of points over $\gamma$-GT-positive ducts, we cal cul ated the vol ume percent of liver occupied by ducts. 3,18

Indirect immunohistochemistry was performed to detect proliferating cellular nuclear antigen (PCN A) in proliferating bile ducts. Briefly, formalin-fixed liver sections were deparaffined, followed by microwave treatment ( 5 minutes in water at $500 \mathrm{~W}$ ). After adequate blocking of endogenous peroxidase activity by methanol-peroxidase solution, nonspecific binding was blocked by incubation with normal goat serum for 30 minutes at room temperature. Sections were incubated with anti-PCN A antibody (clone PC-10; Oncogene Research Products, Cambridge, MA) at $4^{\circ} \mathrm{C}$ overnight. After several washes with cold phosphate-buffered saline, biotin-labeled secondary antibody at a dilution of 1:100 (Dako, K yoto, Japan) was added for 1 hour at room temperature. For detection of this reaction, a peroxidase-label ed avidin-biotin complex with diaminobenzidine (D ojin Chemical Co, K umamoto, Japan) was used as a substrate. Sections were counterstained with hematoxylin and examined with a microscope (Olympus Optical Co., BX 40, J apan); 300-400 cholangiocytes were analyzed for each interval.

\section{In Vivo Measurement of $\left[{ }^{3} \mathrm{H}\right]$ Thymidine Incorporation in Cholangiocytes}

We measured DNA synthesis of pure cholangiocytes from control and $\mathrm{BA}$-fed rats by measuring of $\left[{ }^{3} \mathrm{H}\right]$ thymidine incorporation as described previously. ${ }^{3}$

\section{Measurement of $\mathrm{H}_{3}$-Histone and $\mathrm{SR}$ Gene Expression}

Steady-state levels of $\mathrm{H}_{3}$-histone and $\mathrm{SR}$ messenger RNAs (mRNAs) were measured by the lysate ribonuclease (RN ase) protection assay (Direct Protect kit; Ambion Inc., Austin, TX).3,4 The phenotypic characteristics of cholangiocytes from normal and BA-fed rats were assessed by hybridization with cytokeratin 19 (CK -19), a specific marker of chol angiocytes. ${ }^{3}$ The comparability of the cell lysate used was determined by hybridization with glyceraldehyde-3-phosphate dehydrogenase (GAPDH). ${ }^{2,4,16}$ Antisense mRN A probes were transcribed from sel ected complementary D N A (CDN A) linearized templates using the M axiscript kit (A mbion Inc.). 


\section{Measurement of Intracellular CAMP Levels}

After purification, cholangiocytes $\left(1 \times 10^{5}\right)$ were incubated for 5 minutes at $22^{\circ} \mathrm{C}^{3}$ with $10^{-7} \mathrm{~mol} / \mathrm{L}$ secretin (Peninsula Laboratories, Belmont, CA) or $1 \%$ bovine serum albumin (control), and intracellular CAMP levels were measured by radioimmunoassay (Amersham, Arlington Heights, IL) as described previously. 3,4,16

\section{Measurement of Spontaneous and Secretin-Stimulated Bile Flow}

In control and BA-fed rats, bile secretion and bicarbonate secretion were measured as described. ${ }^{1,3,16}$ Briefly, one jugular vein was incannulated with a PE 50 cannula (ClayA dams, N ew York, NY) to infuse K rebs- $\mathrm{H}$ ensel eit bicarbonate solution ( $\mathrm{KRH}$ ) or secretin dissolved in $\mathrm{KRH}$. When steadystate bile flow was achieved, secretin $\left(10^{-7} \mathrm{~mol} / \mathrm{L}\right)$ was infused for 30 minutes followed by a final infusion of $\mathrm{KRH}$ for 60 minutes. Bile was collected at 10-minute intervals, placed in preweighed tubes, and immediately stored at $-70^{\circ} \mathrm{C}$. Bicarbonate concentration (measured as total $\mathrm{CO}_{2}$ ) in bile was determined with a $\mathrm{N}$ atelson microgasometer apparatus (Scientific Industries, Bohemia, NY). Fasting animal blood was collected for determination of serum BA levels. The levels of total BA in bile or serum were determined by the $3 \alpha$-hydroxysteroid dehydrogenase procedure ${ }^{20}$ using a commercially available kit according to the instructions supplied by the vendor (Wako Chemicals USA, Inc., Richmond, VA). Aliquots of bile extracted with 4 volumes of isopropanol were analyzed for individual bile salt by reverse-phase high-performance liquid chromatography using an acidic isocratic phosphate buffer as previously described. ${ }^{21}$

\section{Statistical Analysis}

All data are expressed as means \pm SE. Differences between groups were analyzed by the Student unpaired t test when 2 groups were analyzed or analysis of variance (AN OVA) when more than 2 groups were analyzed.

\section{Results}

\section{Serum and Bile Concentration and Composition}

There was a significant increase in total BA concentration in bile obtained from TC- or TLC-fed rats compared with control rats (Table 1 ). In contrast, no increase in serum total BA in TC-fed rats and a modest decrease in serum total BA in TLC-fed rats were observed (Table 1). The finding of no increase in serum total $B A$ levels in BA-fed rats indicates that BA feeding with the amount chosen in our experiments does not induce cholestasis. BA composition of bile samples obtained from control and TC- and TLC-fed rats (Table 2 ) shows enrichment of bile with the fed BA.

\section{Determination of Liver Inflammation and Hepatic Damage}

Portal inflammation was not seen in rat liver sections after feeding with TC, TLC, or control diet. $\mathrm{H}$ epatic inflammation scores were similar in rats fed TC, TLC, and control diet (results not shown). Serum levels of SGPT, SG OT, GGT, alkaline phosphatase, and both total and direct bilirubin were not significantly different in BA-fed rats and rats fed a control diet (results not

Table 1. BA Concentration in Bile and Serum and Basal and Secretin-Induced Bile Flow and Biliary Composition in Control, TC-Fed, and TLC-Fed Rats

\begin{tabular}{|c|c|c|c|c|c|c|c|c|}
\hline \multirow[b]{2}{*}{ Treatment } & \multicolumn{2}{|c|}{$\begin{array}{l}\text { BA levels } \\
(m E q / L)\end{array}$} & \multicolumn{2}{|c|}{$\begin{array}{c}\text { Bile secretion } \\
\left(\mu \mathrm{L} \cdot \mathrm{min}^{-1} \cdot \mathrm{kg}^{-1}\right)\end{array}$} & \multicolumn{2}{|c|}{$\begin{array}{l}\text { Bicarbonate concentration } \\
\qquad(m E q / L)\end{array}$} & \multicolumn{2}{|c|}{$\begin{array}{l}\text { Bicarbonate secretion } \\
\left(\mu \mathrm{Eq} \cdot \mathrm{min}^{-1} \cdot \mathrm{kg}^{-1}\right)\end{array}$} \\
\hline & Bile & Serum & Basal & Secretin & Basal & Secretin & Basal & Secretin \\
\hline Control & $2.82 \pm 0.22$ & $0.056 \pm 0.001$ & $91.85 \pm 14.48$ & $86.99 \pm 14.5$ & $24.46 \pm 1.98$ & $27.00 \pm 0.57$ & $2.19 \pm 0.21$ & $2.36 \pm 0.35$ \\
\hline TC, 1 wk & $11.23 \pm 2.54^{a}$ & $0.049 \pm 0.003$ & $126.64 \pm 16.21$ & $136.90 \pm 17.6$ & $22.82 \pm 0.68$ & $32.07 \pm 1.10^{d}$ & $2.71 \pm 0.42$ & $4.54 \pm 0.54^{e}$ \\
\hline TC, 2 wk & $8.76 \pm 0.83^{a}$ & $0.045 \pm 0.004$ & $91.22 \pm 2.25$ & $105.49 \pm 3.2^{c}$ & $28.32 \pm 1.14$ & $30.72 \pm 0.75$ & $2.58 \pm 0.09$ & $3.23 \pm 0.08^{e}$ \\
\hline TC, $3 \mathrm{wk}$ & $8.73 \pm 0.95^{a}$ & $0.064 \pm 0.001$ & $82.56 \pm 7.09$ & $102.68 \pm 6.6^{c}$ & $30.15 \pm 0.27$ & $33.67 \pm 0.33^{d}$ & $2.48 \pm 0.30$ & $3.45 \pm 0.35^{e}$ \\
\hline TC, 4 wk & $6.38 \pm 0.26^{a}$ & $0.032 \pm 0.002$ & $79.97 \pm 7.64$ & $96.84 \pm 6.8^{c}$ & $26.85 \pm 1.35$ & $31.96 \pm 0.75^{d}$ & $2.15 \pm 0.24$ & $2.86 \pm 0.21^{e}$ \\
\hline TLC, 1 wk & $3.15 \pm 1.02^{b}$ & $0.010 \pm 0.002$ & $85.35 \pm 4.44$ & $102.51 \pm 3.3^{c}$ & $29.88 \pm 0.22$ & $34.68 \pm 2.19^{d}$ & $2.54 \pm 0.12$ & $3.57 \pm 0.30^{e}$ \\
\hline TLC, 2 wk & $4.09 \pm 0.57^{a}$ & $0.011 \pm 0.001$ & $65.09 \pm 8.00$ & $75.14 \pm 7.9$ & $29.87 \pm 0.69$ & $32.37 \pm 2.19^{d}$ & $1.95 \pm 0.24$ & $2.42 \pm 0.25^{b}$ \\
\hline TLC, 3 wk & $3.43 \pm 0.19^{a}$ & $0.006 \pm 0.001$ & $88.09 \pm 3.50$ & $100.93 \pm 7.0^{c}$ & $22.67 \pm 2.31$ & $26.35 \pm 0.70^{d}$ & $1.91 \pm 0.21$ & $2.66 \pm 0.16^{e}$ \\
\hline TLC, $4 \mathrm{wk}$ & $3.79 \pm 0.11^{a}$ & $0.009 \pm 0.003$ & $58.83 \pm 3.83$ & $72.95 \pm 4.1^{c}$ & $30.80 \pm 1.32$ & $34.83 \pm 1.56^{d}$ & $1.81 \pm 0.14$ & $2.52 \pm 0.11^{e}$ \\
\hline
\end{tabular}

NOTE. Data are means \pm SE of at least 10 values from control rats and rats fed $1 \%$ TC or $1 \%$ TLC for $1-4$ weeks. BA levels in bile and serum from control and BA-fed rats were measured as described in Materials and Methods using commercially available kits.

${ }^{a} P<0.05$ by the unpaired Student $t$ test compared with the corresponding values of normal control rats. Values are mean $\pm S E$ for 6 - 10 rats and obtained at steady-state conditions of bile flow. After an equilibration period of 60 minutes with KRH solution, secretin was infused via a jugular vein for 30 minutes at $10^{-7} \mathrm{~mol} / \mathrm{L}$.

${ }^{b}$ Not significant.

${ }^{c} P<0.05$ vs. basal bile secretion.

$d P<0.05$ vs. basal bicarbonate concentration of normal control rats.

$e P<0.05$ vs. basal bicarbonate secretion. 
Table 2. BA Composition in Bile Obtained From Control, TC-Fed, and TLC-Fed Rats

\begin{tabular}{lccccc}
\hline Treatment & $\begin{array}{c}\text { Muricholic acid } \\
(\mathrm{mmol} / \mathrm{L})\end{array}$ & $\begin{array}{c}\text { Taurocholic acid } \\
(\mathrm{mmol} / \mathrm{L})\end{array}$ & $\begin{array}{c}\text { Taurochenocholic acid } \\
(\mathrm{mmol} / \mathrm{L})\end{array}$ & $\begin{array}{c}\text { Taurodeoxycholic acid } \\
(\mathrm{mmol} / \mathrm{L})\end{array}$ & $\begin{array}{c}\text { Taurolithocholic acid } \\
(\mathrm{mmol} / \mathrm{L})\end{array}$ \\
\hline Control & $2.16 \pm 0.15$ & $0.58 \pm 0.06$ & $0.05 \pm 0.01$ & $0.02 \pm 0.005$ & Not detectable \\
TC, $1 \mathrm{wk}$ & $3.40 \pm 0.87$ & $6.03 \pm 1.72^{a}$ & $0.22 \pm 0.07$ & $0.48 \pm 0.18^{a}$ & Not detectable \\
TC, 2 wk & $2.96 \pm 0.45$ & $5.65 \pm 0.24^{a}$ & $0.15 \pm 0.06$ & $0.14 \pm 0.03^{a}$ & Not detectable \\
TC, 3 wk & $2.44 \pm 0.22$ & $5.87 \pm 0.71^{a}$ & $0.10 \pm 0.02$ & $0.31 \pm 0.08^{a}$ & Not detectable \\
TC, 4 wk & $1.66 \pm 0.21$ & $4.38 \pm 0.26^{a}$ & $0.06 \pm 0.006$ & $0.24 \pm 0.03^{a}$ & Not detectable \\
TLC, 1 wk & $1.65 \pm 0.11$ & $0.45 \pm 0.09$ & $0.09 \pm 0.009$ & $0.03 \pm 0.006$ & $0.46 \pm 0.14^{a}$ \\
TLC, 2 wk & $2.32 \pm 0.50$ & $0.66 \pm 0.11$ & $0.29 \pm 0.07^{a}$ & $0.028 \pm 0.001$ & $0.34 \pm 0.03^{a}$ \\
TLC, 3 wk & $1.67 \pm 0.24$ & $0.86 \pm 0.10$ & $0.16 \pm 0.02^{a}$ & Not detectable & $0.35 \pm 0.04^{a}$ \\
TLC, 4 wk & $2.15 \pm 0.05$ & $1.11 \pm 0.08$ & $0.22 \pm 0.03^{a}$ & Not detectable & $0.30 \pm 0.05^{a}$ \\
\hline
\end{tabular}

NOTE. Values are means \pm SE of at least 6 rats and were obtained in the first 10 minutes of bile collection. BA composition in bile samples from control, TC-fed, and TLC-fed rats was measured by standard high-performance liquid chromatography.

ap $<0.05$ vs. corresponding value of BA-fed control rats.

shown). The data suggest that BA feeding results in neither hepatocellular necrosis nor cholestasis.

\section{Proliferative Activity of Cholangiocytes From Control and BA-Fed Rats}

Only 2-3 bile ducts (stained for $\gamma$-GT or PCNA) were present in portal areas of liver sections from control rats (Figure 1). A marked increase in the number of bile ducts (stained for $\gamma$-GT or PCNA) per portal area was observed after TC or TLC feeding (Figure 1; at 1 week of feeding, representative experiments). In situ quantitative morphometric analysis showed a marked increase in the number of bile ducts (stained for $\gamma$-GT) after BA feeding for 1-4 weeks compared with control rats (Figure 2). Similarly, the percentage of PCN A-positive cholangiocytes was significantly increased with 1-4 weeks of BA feeding compared with controls (Figure 2). DN A synthe sis of control cholangiocytes, measured by $\left[{ }^{3} \mathrm{H}\right]$ thymidine incorporation, was very low (Figure 3). In contrast, $\left[{ }^{3} \mathrm{H}\right.$ ]thymidine incorporation in purified cholangiocytes was markedly increased after TC or TLC feeding from 1-4 weeks (Figure 3). DNA synthesis, measured as $\mathrm{H}_{3}-$ histone gene expression, was very low in control cholangiocytes (Figure 4). ${ }^{3}$ In contrast, after TC or TLC feeding for 1-4 weeks, there was a marked increase (15-20-fold) in $\mathrm{H}_{3}$-histone gene expression compared with control cholangiocytes (Figure 4). Expression of both GAPDH and CK-19 mRNAs was similar among cholangiocytes from control and BA-fed rats (Figures 4 and 5).

\section{Secretory Activity of Cholangiocytes From Control and BA-Fed Rats}

Parallel to increased ductal proliferation observed in BA-fed rats, SR gene expression increased (2-3-fold) in
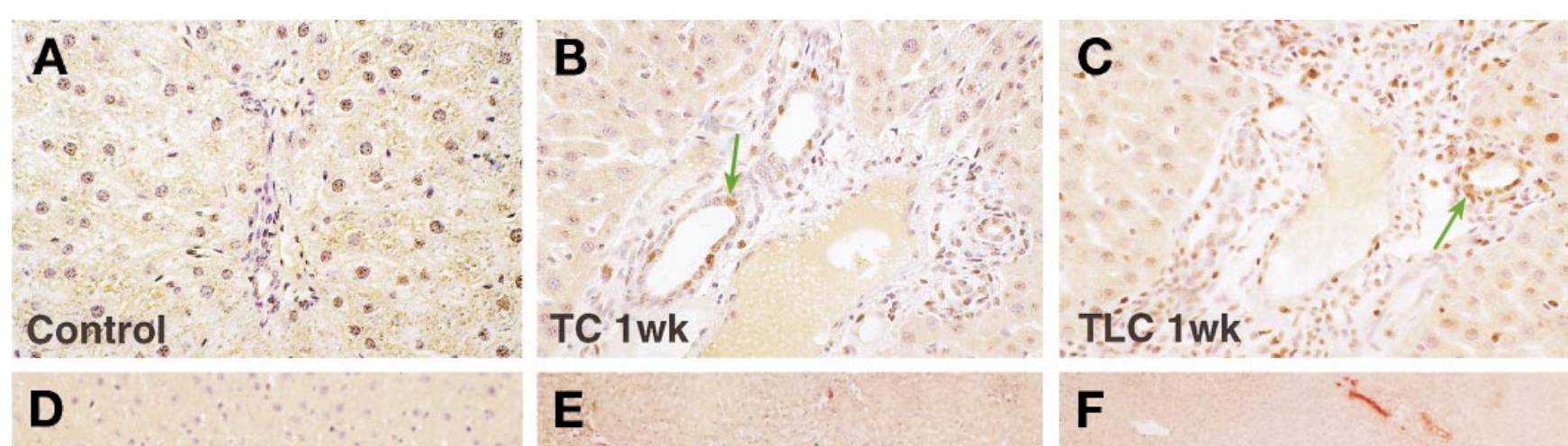

D

\section{Control}
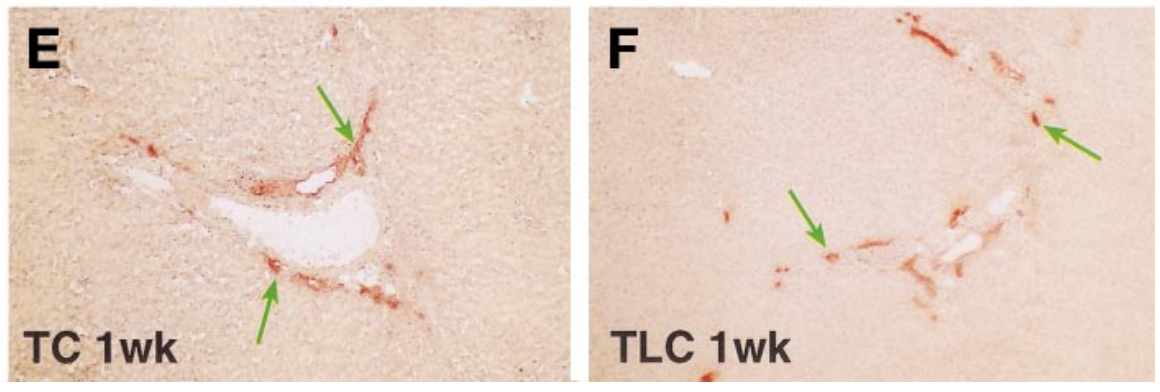

Figure 1. Staining for ( $A-C)$ PCNA and $(D-F) \gamma$-GT in sections from $(A$ and $D)$ control, $(B$ and $E$ ) TC-fed, or ( $C$ and $F)$ TLC-fed rats. After TC and TLC feeding (at 1 week, a representative experiment), there was a marked increase in the number of PCNA-positive cholangiocytes and bile ducts (original magnifications $125 \times$ and $160 \times ; \gamma$-GT staining in control rats). Arrows indicate cholangiocytes and bile ducts positive for PCNA or $\gamma$-GT, respectively. 

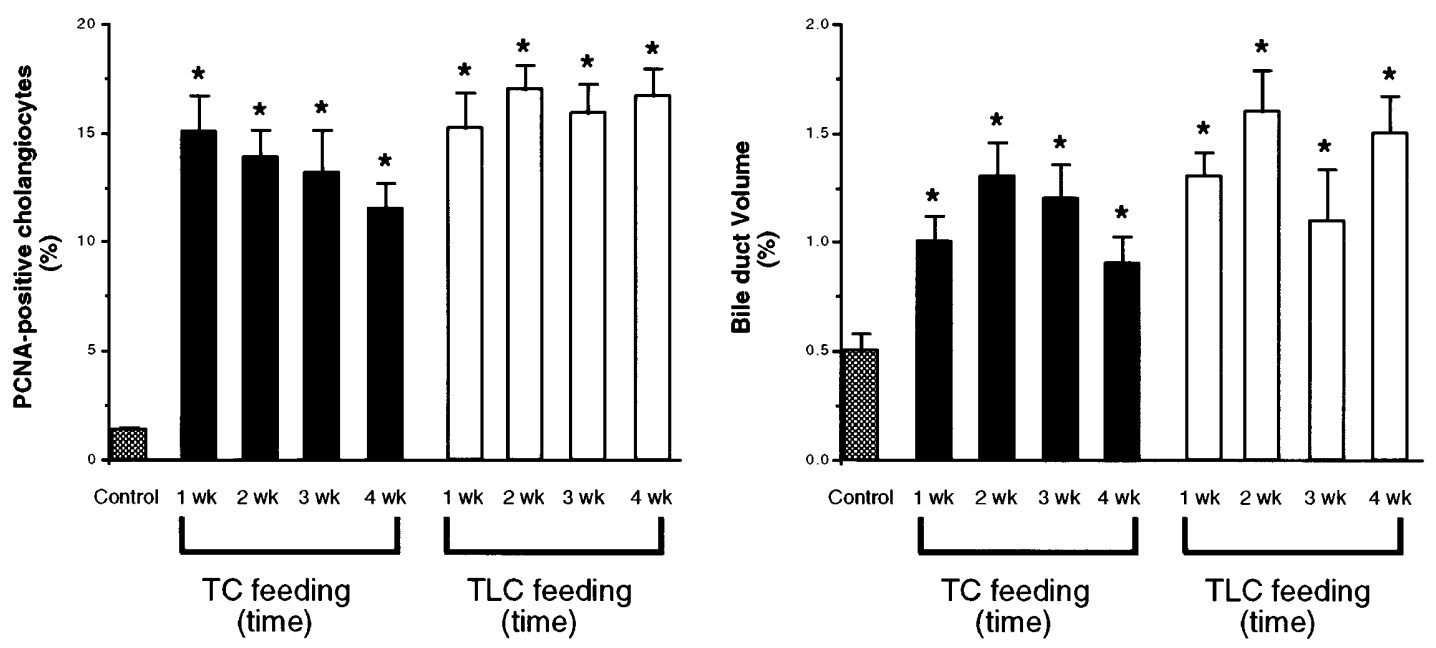

Figure 2. In situ quantitative morphometric analysis of the number of PCNA-positive cholangiocytes and number of bile ducts in liver sections stained for $\gamma$-GT (see Materials and Methods). For each interval, 300-400 cholangiocytes were analyzed. $* P<0.05$ vs. control rats.

cholangiocytes from both TC- and TLC-fed rats compared with control cholangiocytes (Figure 5). Basal intracellular CAMP levels in cholangiocytes from TC- or TLC-fed rats were similar to those in control cholangiocytes (Figure 6). Although secretin significantly increased CAMP levels in cholangiocytes from rats fed a control diet, the increases in CAMP levels were significantly greater $(P<0.05)$ in cholangiocytes from rats fed TC or TLC for 1-4 weeks (see Figure 6). The effects of BA feeding on bile and both bicarbonate concentration and secretion are shown in Table 1. TC or TLC feeding resulted in increases in secretin-induced bile flow and both bicarbonate concentration and secretion (Table 1). The findings of increased SR gene expression, secretin-

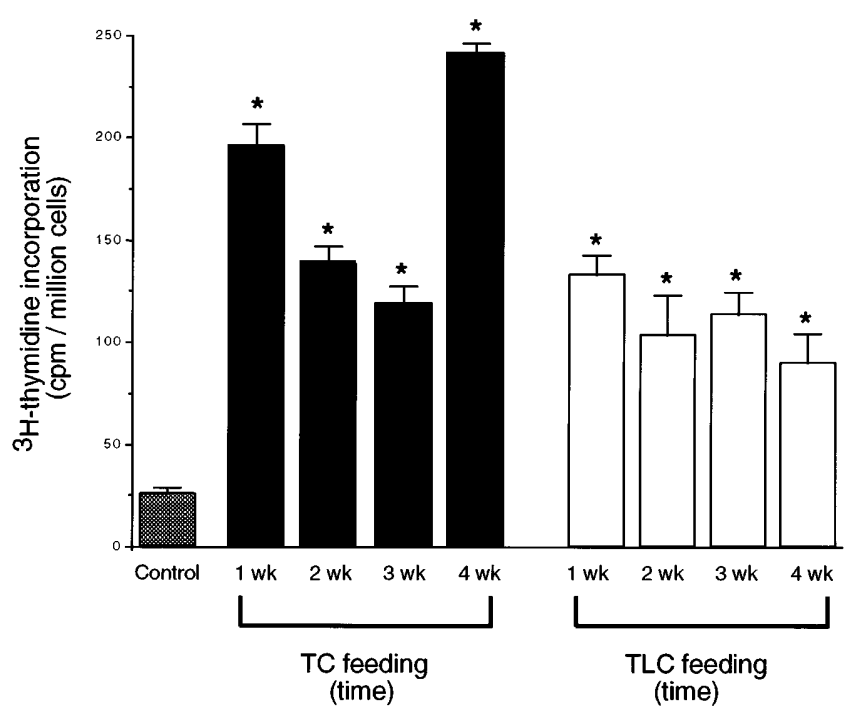

Figure 3. Ninety minutes after an intraperitoneal administration of 1 $\mu \mathrm{Ci} / \mathrm{g}$ body wt of [methyl- ${ }^{3} \mathrm{H}$ ]thymidine, the radioactivity incorporated into DNA was measured in cholangiocytes from control, TC-fed, and TLC-fed rats. $* P<0.05$ compared with control cholangiocytes. Data are means $\pm S E$ of 3 experiments. stimulated CAM P synthesis in cholangiocytes, and secretin-stimulated bile flow and bicarbonate secretion are consistent with increased duct secretion in BA-fed rats.

\section{Discussion}

Our studies show that after feeding, BAs in vivo interact with cholangiocytes and stimulate proliferative and secretory processes of these cells. There was an increase in the number of bile ducts in BA-fed rats compared with control rats with the absence of biochemical or histological evidence of hepatic injury or cholestasis. Parallel with changes in ductal mass, DN A synthesis, SR gene expression, and secretin-stimulated CAMP levels

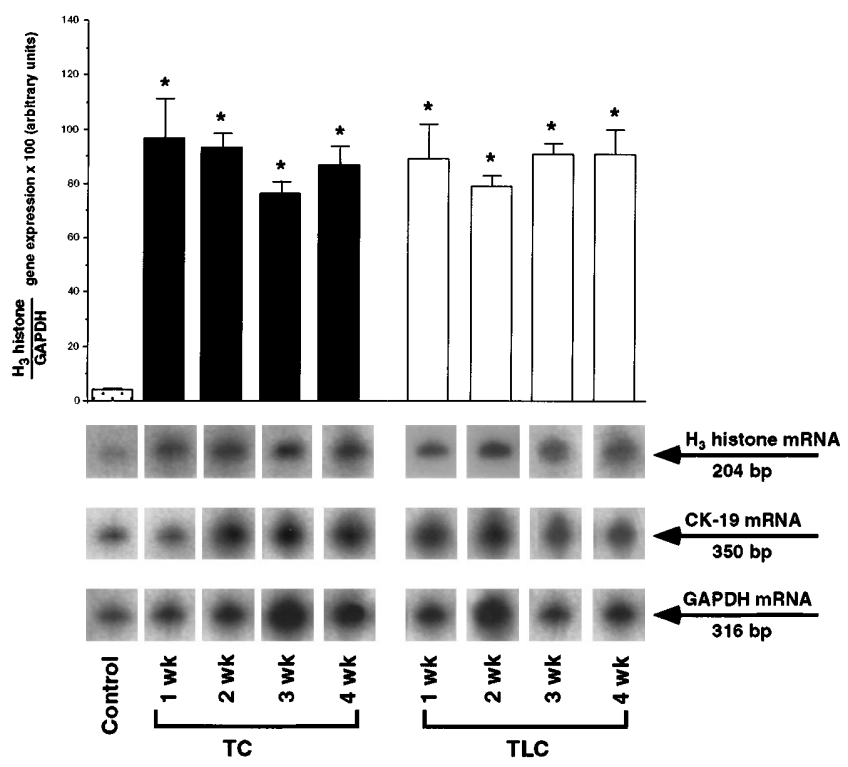

Figure 4. Expression of selected messages was determined by direct RNase protection assay using cell lysate samples, each containing $4.50 \times 10^{5}$ pure cholangiocytes from control and BA-fed rats. Autoradiograms $(n=3)$ were quantified by densitometry. 


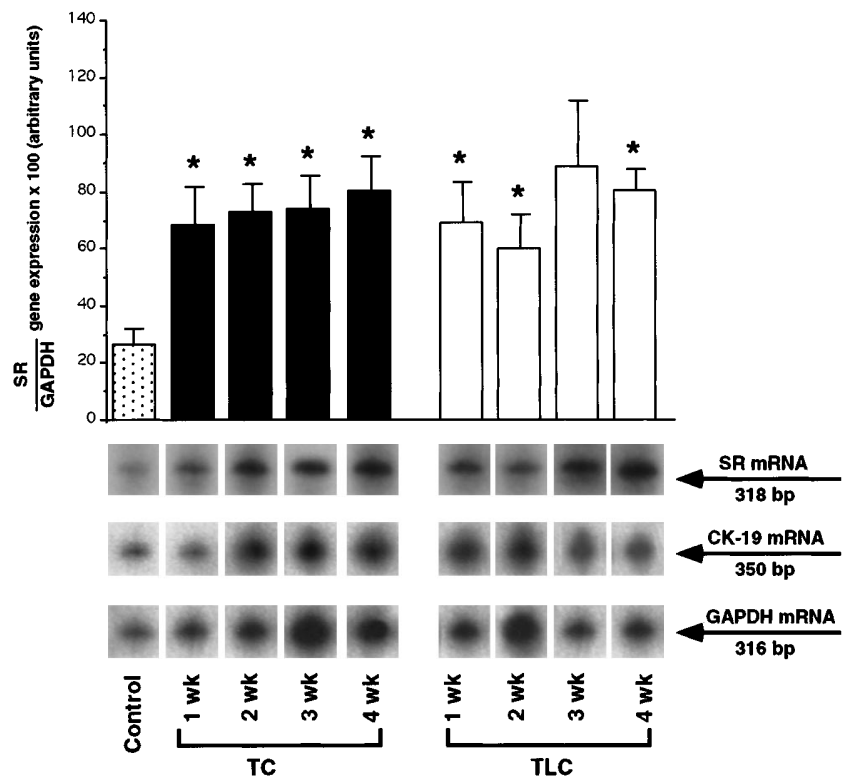

Figure 5. Genetic expression of SR in cholangiocytes from control and BA-fed rats. Molecular analysis was performed by RNase protection assays using cell lysate samples each containing $4.50 \times 10^{5}$ cholangiocytes. Data are mean \pm SE of 3 experiments.

all markedly increased in cholangiocytes from BA-fed rats compared with control rats. In vivo, secretin markedly increased bile flow and both biliary bicarbonate concentration and secretion in BA-fed rats compared with absence of secretin-induced ductal secretion in controls. The data suggest that BAs modulate ductal bile secretion in the normal state and may induce ductal proliferation in the disease state (with BA accumulation).

W hen circulatory levels of $B A$ are elevated with cholestasis, BA may be toxic to hepatocytes because of changes in hepatocyte $\mathrm{Ca}^{2+}$ and $\mathrm{Mg}^{2+}$, as shown by Spivey et al., ${ }^{9}$ and adenosine triphosphate depletion. ${ }^{10}$ In the BA-fed rat model, cholangiocytes respond with increased proliferation and secretion in the absence of biochemical or histological evidence of hepatocyte injury or cholestasis. Similar effects with both TC and the more potentially hepatotoxic TLC were noted in these studies, showing that BAs per se, not their toxicity potential, cause changes in the BA-fed model. Although short-term TLC administration produces severe chol estasis in rats ${ }^{22}$ and cholestasis and fibrosis in rabbits, ${ }^{23}$ our current study and a previous study ${ }^{22}$ showed that long-term TLC administration in rats does not produce cholestasis or hepatic injury. ${ }^{24}$ Progressive increases in proliferation and secretion were not observed after 1 week of BA feeding. Counterbalancing factors may come into play after 1 week that down-regulate cholangiocyte proliferation and ductal secretion. The present findings contrast with other models of ductal hyperplasia induced by injury, toxins, or cholestasis (e.g., 1-naphthylisothiocyanate feeding and $B D L$ ) in which cholangiocytes progressively proliferate up to 1 month. ${ }^{1}$ Similar to our findings in cholangiocytes, BAs have been shown to stimulate hepatocyte proliferation associated with partial hepatectomy ${ }^{25}$ and pancreatic acinar secretion. ${ }^{26}$

These data provide new insights into the physiological role of BA in the intrahepatic biliary ductal system. We have shown that BAs are absorbed by the apical membrane of cholangiocytes because of the presence of the $\mathrm{N} \mathrm{a}^{+}$-dependent BA transporter, ABAT, ${ }^{12}$ and that $\mathrm{N} \mathrm{a}^{+}$dependent $B A$ transport in cholangiocytes is regulated by secretin. ${ }^{27} \mathrm{Na}^{+}$-dependent BA uptake across the apical membrane of cholangiocytes appears to be required for BA s to alter cholangiocyte function because in vitro, BAs increase cholangiocyte proliferation and ductal secretion
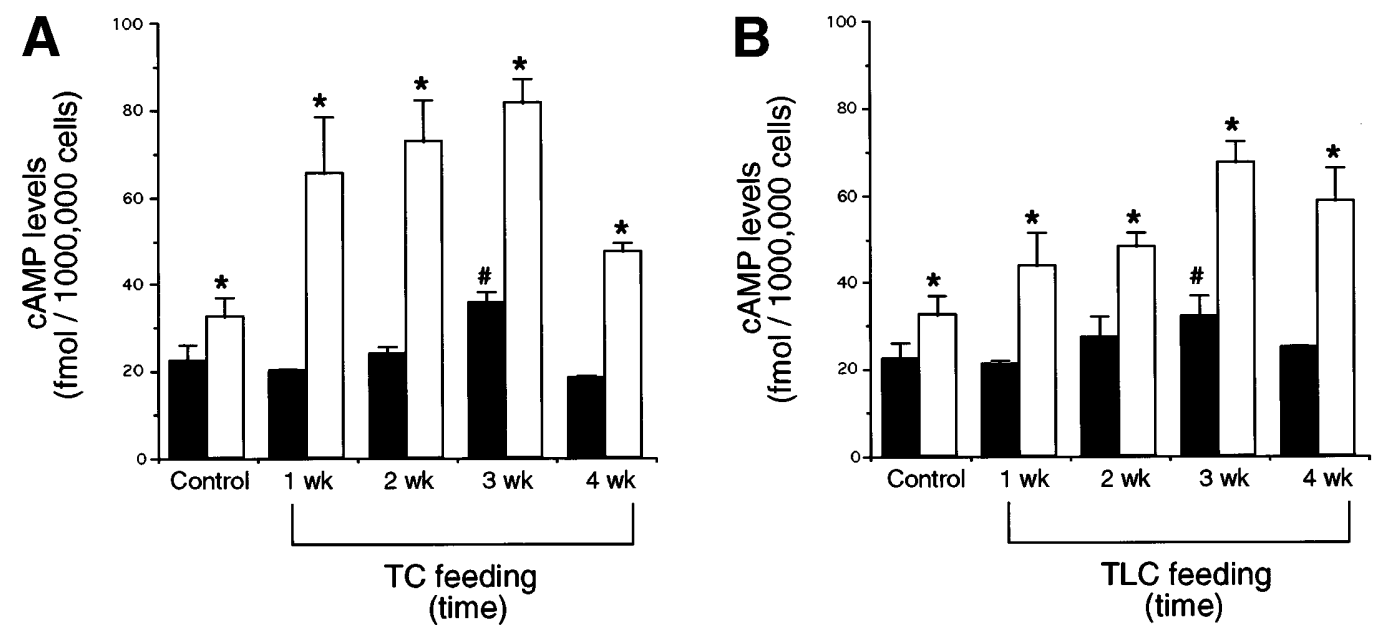

Figure 6. Intracellular CAMP levels in cholangiocytes from control and rats fed $(A) 1 \%$ TC and $(B) 1 \%$ TLC for $1-4$ weeks. $* P<0.05$ vs. basal value. $\# P<0.05$, secretin-induced CAMP levels of cholangiocytes from BA-fed rats differing from secretin-induced cAMP levels of cholangiocytes from control rats. Data are mean \pm SE of 6 experiments. 
only in the presence of $\mathrm{Na}^{+}{ }^{4}$ This study shows that exposure of increased BA levels to the apical (bile) but not basolateral (blood) cholangiocyte membrane stimulates cholangiocyte proliferation and ductal secretion. The studies do not exclude the possibility that high circulating BA levels, which occur in cholestasis, may also directly al ter chol angiocyte function. Our previous experiments show that only certain-sized bile ducts (large but not small) respond to $B A$ and that the distribution of ABAT resides in the same-sized ducts. ${ }^{4}$ Similar correla tion exists between the amount of solute load handled by different kidney tubule segments and the degree of tubul ehyperplasia and hypertrophy. ${ }^{28}$ Because it has been suggested that kidney tubule hyperplasia/hypertrophy compensates for the increased sol ute load, ${ }^{28}$ we speculate that bile duct hyperplasia in BA-fed rats is compensating for increased biliary BAs. Additional studies showing increased transport activity of ABAT in cholangiocytes from BA-fed rats would support this concept. In addition to ABAT, another BA transport system has been demonstrated in cholangiocytes, ${ }^{6}$ but the properties of this transporter make it an unlikely candidate target for BA effects on chol angiocyte function because it has a basolateral location and no dependence on $\mathrm{Na}^{+}$.

The intracellular signaling mechanisms for BAstimulated cholangiocyte secretion and growth have not been established. Because BA s directly stimulate cholangiocyte CAMP synthesis, ${ }^{4}$ and elevated cholangiocyte CAMP levels are present in cholangiocyte hyperplasia, ${ }^{16}$ CAMP is one likely signal. Consistent with this idea, preliminary data from our laboratory suggest that reduction of high biliary $B A$ concentrations in $B D L$ rats reduces cholangiocyte CAM $P$ level s and reverses increased cholangiocyte proliferation. ${ }^{29}$ Other preliminary studies from our laboratory show that ursodeoxycholic acid (UDCA), which does not alter CAMP levels, fails to increase cholangiocyte proliferation or secretion in normal cholangiocytes. ${ }^{4}$ In contrast, we have observed that in UDCA-treated cholangiocytes from BDL rats and in UDCA-fed BDL rats, 30 the el evated cholangiocyte CAM P levels and increased chol angiocyte proliferation and secre tion associated with BDL are ablated. Thus both up- and down-regulation of cholangiocyte proliferation and secre tion by BAs are linked to cholangiocyte CAM P synthesis.

\section{References}

1. Alpini G, Lenzi R, Sarkozi L, Tavoloni N. Biliary physiology in rats with bile ductular cell hyperplasia. Evidence for a secretory function of proliferated bile ductules. J Clin Invest 1988;81:569578.

2. Alpini G, Ulrich II C, Phillips J, Pham L, Miller L, LaRusso N. Upregulation of secretin receptor gene expression in rat cholangiocytes after bile duct ligation. Am J Physiol 1994;266:G922G928.
3. LeSage G, Glaser S, Gubba S, Robertson WE, Phinizy JL, Lasater $J$, Rodgers R, Alpini G. Regrowth of the rat biliary tree after $70 \%$ partial hepatectomy is coupled to increased secretin-induced ductal bile secretion. Gastroenterology 1996;111:1633-1644.

4. Alpini G, Glaser S, Robertson W, Phinizy JL, Rodgers R, Caligiuri A, LeSage $G$. Bile acids stimulate proliferative and secretory events in large but not small cholangiocytes. Am J Physiol 1997;273: G518-G529.

5. Lazaridis KN, Pham L, Tietz P, Marinelli RA, deGroen P, Levine $S$, Dawson $\mathrm{P}$, Larusso NF. Rat cholangiocytes absorb bile acids at their apical domain via the ileal sodium-dependent bile acid transporter. J Clin Invest 1997;100:2714-2721.

6. Benedetti A, Di Sario A, Marucci L, Svegliati-Baroni G, Schteingart CD, Ton-nu H-T, Hofmann AF. Carrier-mediated trans port of conjugated bile acids across the basolateral membrane of biliary epithelial cells. Am J Physiol 1997;35:G1416-G1424.

7. Gurantz D, Hofmann AF. Influence of bile acid structure on bile flow and biliary lipid secretion in the hamster. Am J Physiol 1984;247:G736-G748.

8. Palmer RH, Ruban Z. Production of bile duct hyperplasia and gallstones by lithocholic acid. J Clin Invest 1966;45:1255-1267.

9. Spivey JR, Bronk SF, Gores GJ. Glycochenodeoxycholate-induced lethal hepatocellular injury in rat hepatocytes. Role of ATP depletion and cytosolic free calcium. J Clin Invest 1993;92: 17-24.

10. Patel T, Bronk SF, Gores GJ . Increases of intracellular magnesium promote glycodeoxycholate-induced apoptos is in rat hepatocytes. J Clin Invest 1994;94:2183-2192.

11. Poupon RE, Balkau B, Eschwege E, Poupon R. A multicenter, controlled trial of ursodiol for the treatment of primary biliary cirrhosis. N Engl J Med 1991;324:1548-1554.

12. Alpini G, Glaser S, Rodgers R, Phinizy JL, Robertson WE, Lasater J, Caligiuri A, Tretjak Z, LeSage G. Functional expression of the apical $\mathrm{Na}^{+}$-dependent bile acid transporter in large but not small rat cholangiocytes. Gastroenterology 1997;113:1734-1740.

13. Pandak W, Vlahcevic Z, Heuman D, Redford K, Chiang J, Hylemon P. Effects of different bile salts on steady-state mRNA levels and trans criptional activity of cholesterol 7 alpha-hydroxylase. Hepatology 1994;19:941-947.

14. Strange E, Scheibner J, Lutz C, Ditschuneit H. Feedback regulation of bile acid synthesis in the rat by dietary vs. intravenous cholate or taurocholate. Hepatology 1988;8:879-886.

15. Davis B, Madri J. Type I and type III procollagen peptides during hepatic fibrinogenesis. Am J Pathol 1987;126:G137-G147.

16. Glaser S, Rodgers R, Phinizy J L, Robertson W, Lasater J, Caligiuri A, Tretjak Z, LeSage G, Alpini G. Gastrin inhibits secretin-induced ductal secretion by interaction with specific receptors on rat cholangiocytes. Am J Physiol 1997;273:G1061-G1070.

17. Ishii M, Vroman B, LaRusso NF. Isolation and morphological characterization of bile duct epithelial cells from normal rat liver. Gastroenterology 1989;97:1236-1247.

18. Weibel ER, Gomez D. A principle for counting tissue structure on random sections. Appl Physiol 1962;17:3443-3448.

19. Rutemberg AM, Kim H, Fishbein JW, Hanker JS, Wasserkrug HL, Seligman AM. Histochemical and ultras tructural demonstration of $\gamma$-glutamyl transpeptidase activity. J Histochem Cytochem 1969; 17:517-526.

20. Mashige F, Tanaka N, Maki A, Kamei S, Yamanaka M. Direct spectrophotometry of total bile acids in serum. Clin Chem 1981;27:1352-1356.

21. Cantafora A, Di Biase A, Alvaro D, Angelico M. An improved method for measuring the glycine and taurine conjugates of bile salts by high performance liquid chromatography with tauro-7alpha-, 12 alpha, dihydroxy-5-beta-cholanic acid. J Chromatogr 1987;386:367-370. 
22. Kitani K. The protective effect of hydrophilic bile acids on bile acid hepatoxicity in the rat. Ital J Gastroenterol 1995;27:366-371.

23. Fischer C, Cooper N, Rothschild M, Mosbach E. Effect of dietary chenodeoxycholic acid and lithocholic acid in the rabbit. Am J Dig Dis 1974;19:877-886.

24. Gratton F, Weber A, Tuchweber B, Morazain R, Roy C, Yousef I. Effect of chronic administration of taurolithocholate on bile formation and liver ultrastructure in the rat. Liver 1987;7:130137.

25. Barone $M$, Francavilla $A$, Polimeno $L$, lerardi $E$, Romanelli $D$, Berloco P, Di Leo A, Panella C. Modulation of rat hepatocyte proliferation by bile salts in vitro and in vivo studies. Hepatology 1996;23:1159-1166.

26. Shinozaki H, Funakoshi A, Miyasaka K, Kitani K. Stimulatory effect of ursodeoxycholate on pancreatic exocrine secretion in an in vitro study. Pancreas 1995;10:246-250.

27. Alpini G, Glaser S, Phinizy JL, Caligiuri A, Robertson W, Lasater J, Rodgers R, Tretjak Z, LeSage G. Secretin-dependent insertion of the $\mathrm{Na}^{+}$-dependent bile acid transporter on the cholangiocyte apical membrane regulates ductal reabsorption of bile acids and ductal bile secretion in bile duct ligated (BDL) rats (abstr). Hepatology 1997;26:A529.

28. Fine LG, Norman JT, Kujubu DA, Knecht A. Renal hypertrophy. In:
Seldin DW, Giebisch G, eds. The kidney: physiology and pathophysiology. 2nd ed. New York: Raven, 1992:3113-3133.

29. Alpini G, Glaser S, PhinizyJ L, Rodgers R, Robertson W, Caligiuri A, Lasater J, Tretjak Z, LeSage G. Bile acid depletion decreases cholangiocyte proliferative capacity and secretin-stimulated ductal bile secretion in bile duct ligated rats (abstr). Gastroenterology 1997;112:A1210.

30. Alpini G, Glaser S, Caligiuri A, Phinizy J, Rodgers R, Francis $H$, Robertson W, Papa E, Lasater J, LeSage G. Ursodeoxycholic acid feeding inhibits secretin-induced cholangiocyte secretory processes in bile duct ligated rats (abstr). Gastroenterology 1998; 114:AL0016.

Received March 5, 1998. Accepted October 13, 1998.

Address requests for reprints to: Gene D. LeSage, M.D., Texas A\&M University College of Medicine, 2401 South 31st Street, Temple, Texas 76508. e-mail: gdl2237@tamu.edu; fax: (254) 7715725.

Supported by a grant award to Drs. Alpini and LeSage from Scott \& White Hospital and Texas A\&M University (to G.A. and G.D.L) and by a Veterans Administration Merit Award (to G.A.). 